\title{
Social Stratification and Mobility in Central Veracruz
}

Social Stratification and Mobility in Central Veracruz es la tercera de una serie de obras de Hugo Nutini sobre el tema de la sociedad superordinada en México. El primero de estos trabajos, The Wages of Conquest. The Mexican Aristocracy in the Context of Western Aristocracies (1995), trata la colocación de la aristocracia mexicana vis-à-vis sus semejantes occidentales, entendidos éstos como europeos. La conclusión principal a que llegó en ese primer libro fue que durante su crecimiento y declive (1519-1900) los residuos de la grandeza colonial en México siempre representaron una copia marginal y pobre del modelo europeo. A partir de esa aseveración, el autor adelantó la idea, recurrente en sus siguientes trabajos, de que el estudio de la aristocracia nos podría proporcionar revelaciones acerca de la estructura y mentalidad de las clases subordinadas.

Los principales ejes que proporcionan el cimiento de The Wages of Conquest vuelven a aparecer en The Mexican Aristocracy: an Expressive Ethnography, 1910-2000 (2004). Aunque para el periodo cubierto en

Hugo G. Nutini. Social Stratification and Mobility in Central Veracruz. University of Texas Press, Austin, 2005, pp. xi +178. este libro la aristocracia mexicana se encontraba en pleno retroceso en el mundo material, todavía podía movilizar influencias sustanciales en el campo expresivo de los demás componentes de la clase dominante. No obstante la emergencia de una creciente plutocracia después de la Revolución, especialmente a partir de la década de 1950, esta clase media alta asumiría aspectos expresivos y de comportamiento de esa aristocracia venida a menos.

El tercer libro, Social Stratification..., retoma la cuestión donde terminó el segundo, pero ahora el análisis no se hace a escala nacional -es decir, básicamente en el Distrito Federal- sino regional. Para elaborar su estudio de caso, Nutini eligió la ciudad de Córdoba, en el centro del estado de Veracruz, y su área circundante. Sostiene en este tomo las ideas centrales que había elaborado desde 1995: si bien afirma que el estudio regional revela ciertas distinciones en cuanto actitudes de clase e ideas sobre la movilidad social se trata, mantiene la idea general de que la aristocracia - la copia marginada del modelo europeo- ha marcado el paso para movimientos de ascenso. De tal forma, por lo menos para los actores del sector superordinado, un tema recurrente es la necesidad de la 
blancura como un valor extremadamente deseable, con la excepción de un caso, como veremos abajo. Sin embargo, tal y como sucedía con frecuencia durante el periodo colonial, la falta de blancura era superable por medio de una serie de estrategias.

La introducción y el capítulo 1 del libro dibujan el marco que emplea Nutini, enfatizando la necesidad de combinar dos enfoques sobre la cuestión de la movilidad social: una visión estándar estructural de clase social a la vez que un análisis de aspectos expresivos que se relacionan con movilidad y posición social. Esta parte del libro está escrita de manera concisa siendo, en gran parte, una forma abreviada de sus resultados previos.

El capítulo 2 nos conduce a hacer un recorrido por la región de Córdoba desde la perspectiva de su historia, demografía y geografía. Los tres capítulos restantes tratan los tres strata sociales básicos que identifica Nutini: el sector superordinado, las clases media y trabajadora, y los desposeídos. En el primero de estos casos (compuesto por la plutocracia, la clase media alta y la clase política), hay una diferencia sustancial cuando se compara con la aristocracia del Distrito Federal: en Córdoba, el sistema de haciendas fue efectivamente destruido desde la década de 1930 y los ex propietarios se mudaron o se dedicaron a otras actividades. Sin embargo, sus colaboradores más cer- canos se quedaron y se han constituido en aristócratas sustitutos, que proporcionan referentes para el comportamiento expresivo. En gran parte, la plutocracia está formada por immigrantes (españoles, italianos, libaneses, sirios y palestinos) o sus descendientes; este grupo pudo reclamar su calidad de blancos como un valor distintivo. Sin embargo, la gran riqueza que han acumulado los conduce hacia un consumismo conspicuo, cosa que no cuadra con la herencia aristocrática custodiada por la clase media alta. La clase política constituye la excepción respecto de la blancura: ya que la identidad nacional ha sido construida en torno al mestizaje, los políticos cordobeses se declaran mestizos aun cuando bien podrían pasar por blancos.

El segundo stratum incluye las clases media y media baja, así como la de los trabajadores. Nutini nos informa que es en este grupo general donde encontramos la mayor movilidad social. Hacia la parte superior de la escala, la adquisición de riqueza material y su defensa son preocupaciones importantes, mientras que el sector superordinado ofrece los modelos expresivos a seguir. En la parte inferior del grupo, parece que los actores se preocupan más por la distinción entre trabajadores de cuello blanco y de cuello azul. Para estos strata bajos, el color asume un papel de menor importancia en la defini- 
ción del posicionamiento que la educación, la cual es condicionante para la consecusión de una mejor vida aun cuando, a fin de cuentas, es posible que los hijos que reciben una mejor educación asuman el juego de actitudes y comportamientos de las clases sociales superiores.

Finalmente se consideran a los desposeídos; en este caso Nutini se refiere a los trabajadores rurales y campesinos de subsistencia. Estas personas reciben poca atención en el libro: "The rural lower middle and working classes can only be understood as an extension of the urban, national class structure [...]" (p. 107). Esta afirmación permite cierta crítica de la naturaleza lineal de la construcción general que hace Nutini: es decir, hay o había una aristocracia occidental que se imponía en las colonias; a su vez, estas clases dominantes (proto) nacionales escribieron las reglas para las clases inferiores y para los primos locales y regionales. En esta visión de movilidad social y de clase existe poca posibilidad para que los actores sociales actuen, y en cuanto a lo dicho sobre la relación de los trabajadores rurales con el contexto urbano, esta afirmación ignora estudios recientes sobre la nueva ruralidad.
Para un lector extr.unjero, este libro presenta una mirada interesante y concisa de la socicdad cordobesa. Sin embargo, para el lector especilizado o mexicano, le falta detalle y descripción del objeto de investigación, especialmente en cuanto al uso del concepto de región se refiere. Un ejemplo: a veces la vecina ciudad de Orizaba entra en el análisis y luego es excluída, a la vez que siempre es mencionada la comunidad indígena de Tequila, cuyo centro regional es Orizaba. Nutini terminó la investigación para este libro en 1998: en tanto menciona la importancia de la migración estacional a Estados Unidos, eventos más recientes, como la salida masiva a la Unión Americana y sin el sentido estacional, alimentada con trabajadores de todos los sectores con excepción de la clase política y la plutocracia, amenazan con una disrupción de la estructura social y sus expectatitivas.

David Skerritt Gardner Instituto de Investigaciones Histórico-Sociales, Universidad Veracruzana 